\title{
HISTOCHEMICAL DEMONSTRATION OF CATECHOLAMINES IN THE TOAD SYMPATHETIC GANGLIA
}

\author{
Shinji HONMA \\ Department of Physiology, Niigata University, School of Medicine \\ Niigata City, Japan.
}

It was proposed in A previous paper (HonMA, in preparation) that there would be a distributional differences between the two efferent conduction systems of the toad sympathetic ganglia. The $\mathrm{sB}$ system would innervate the toxic gland of the skin, which was assumed to be composed of relatively large neurons and to have myelinated $\mathrm{B}$ pre-and postganglionic fibres. The sC system would innervate the vascular systems of the lower limb, which was assumed to be composed of smaller neurons than the $\mathrm{sB}$ neurons and to have non-myelinated $\mathrm{C}$ pre-and postganglionic fibres.

It was also assumed by simple pharmacological experiments mentioned in the previous paper that both $\mathrm{sB}$ and $\mathrm{SC}$ systems would be adrenergic or catecholamine containing ones, and so the myelinated adrenergic nerve fibres might be present in toad sympathetic nervous system. So a further investigation was attempted to discover the catecholamines in the toad sympathetic nervous system, especially in lumber sympathetic ganglia and the toxic gland of the skin.

\section{MATERIALS AND METHOD}

The histochemical procedure was almost the same as that of Falck and Hillarp (FAlCK and OWMAN, 1965) and with a few variations (Honma, 1969). Various tissues of the toad (Bufo vulgaris japonica) were dissected as quickly as possible and frozen in a dry ice-aceton mixture. Freeze drying time in vacuo was two days or more according to the volume and the number of the tissues. The exposure of the dried tissues to formaldehyde gas was performed in closed vessels with a relative humidity of about $60 \%$ at about $80^{\circ} \mathrm{C}$ for three hours. They were embedded in paraffin in vacuo and serially sectioned at 7 micra in thickness. The sectioned preparations were mounted on noncolosive slide glass in liquid paraffin and warmed for a suitable time at about $60^{\circ} \mathrm{C}$ in order to melt the paraffin into the liquid paraffin. They were observed under a fluorescence microscope of Tiyoda FM $200 \mathrm{~A}$ using Osram $200 \mathrm{~W}$ as a source of light and dark-field super wide condensor for oil immersion of

Received for publication August 1, 1969 本間信治 
Tiyoda. Activation and absorption filters were Schott BG 12 and OG4 respectively. Photomicrographs were taken on Sakura colour films ASA 100 with exposure time of 10 to $30 \mathrm{sec}$.

The observed tissues were as follows; ninth and tenth sympathetic ganglia, the sympathetic ganglia from which splanchnic nerve originated (4,5 and 6th ganglion), the ganglion where bilateral splanchnic nerves fused under the abdominal aorta and vein, toxic gland of the skin and some of the organs which were thought to be innervated by splanchnic nerves. Adrenal medulla, carotid labyrinth, gastrocnemius muscle and atrium of heart were sometimes used. Vascular systems of the lower limb was excluded in these tests.

The sympathetic ganglia of which pre- and postganglionic nerve fibres were cut off were observed in five cases under the fluorescence microscope. After the incision of the dorsal skin and muscle layers to approach the ganglion, pre- and postganglionic fibres of a ganglion of one side were cut off under the stereoscopic microscope with combination of urethane injected intraperitoneally and ether anesthesia. The other side ganglia were kept intact as controls. After 14 days, both sides of the sympathetic ganglia were taken off and treated in the same manners.

Reserpinization was carried out in four cases as follows; three specimens were injected with reserpine of $2.5 \mathrm{mg} /$ day for three days intraperitoneally, one specimen was injected $2.5 \mathrm{mg} /$ day for three days and $5.0 \mathrm{mg} /$ day for a day.

The fluorescence specificity of catecholamines was tested by sodium borohydride treatment i. e. $0.1 \%$ sodium borohydride solved in $95 \%$ isopropyl alcohol (CORRODI et al., 1964).

\section{RESULTS}

\section{Ninth and tenth sympathetic ganglia}

Green to yellowish green fluorescence was seen in relatively large and small nerve cells with various intensity, (FIG. 1, 2). The nuclei of the nerve cells were seen as round or oval fluorescent negative areas in the somata (FIG. 3). No relationships were recognized between the intensity of the fluorescence and the size of the perikarya (FIG. 1, 2 and 3). Analogous neurons which were supposed to be the S.I.F. cells (small intensely fluorescent cells) seen in superior cervical sympathetic ganglion of the rat (NORBERG, RITZÉN and UnGERSTEDT, 1966) were not found in this material. Differences of fluorescence colour tone were not visible in the various size cell bodies with naked eye. Axons were seen in the ganglion, which had a more yellowish fluorescence than is usual. These were supposed to be myelinated B fibres in view of their large caliber and random constrictions which were considered to be the nodes of Ranvier (FIG. 2 arrows). In a few cases, the picture was obtained of an axon that was just protruding from a neuron soma, though it was difficult to trace the axon for a long distance from the axonhillock to the first myelination (FIG. 4A, B). Axons with a fine caliber just leaving from the small neurons which might be considered to be $\mathrm{sC}$ neurons were not encountered. Fluorescent nerve fibres with varicosities around the postganglionic neurons or in close contact with them, which might be con- 


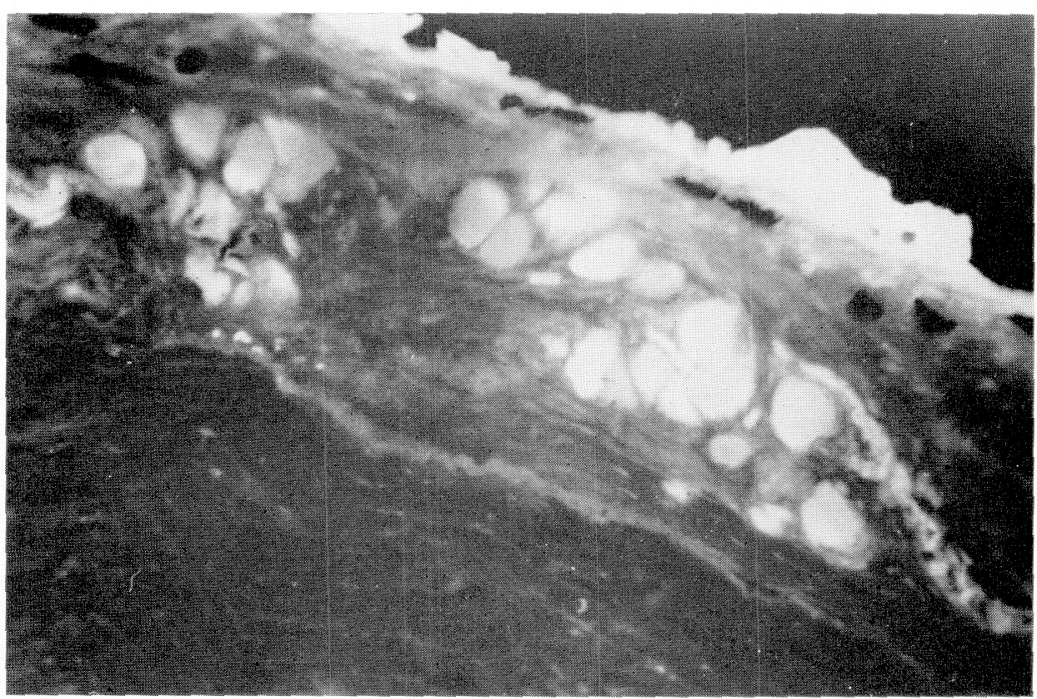

FIG. 1. Tenth prevertebral sympathetic ganglion on the tenth spinal nerve (left lower region of the photomicrograph). Fluorescence is seen in various size neurons with various intensity. $\times 100$.

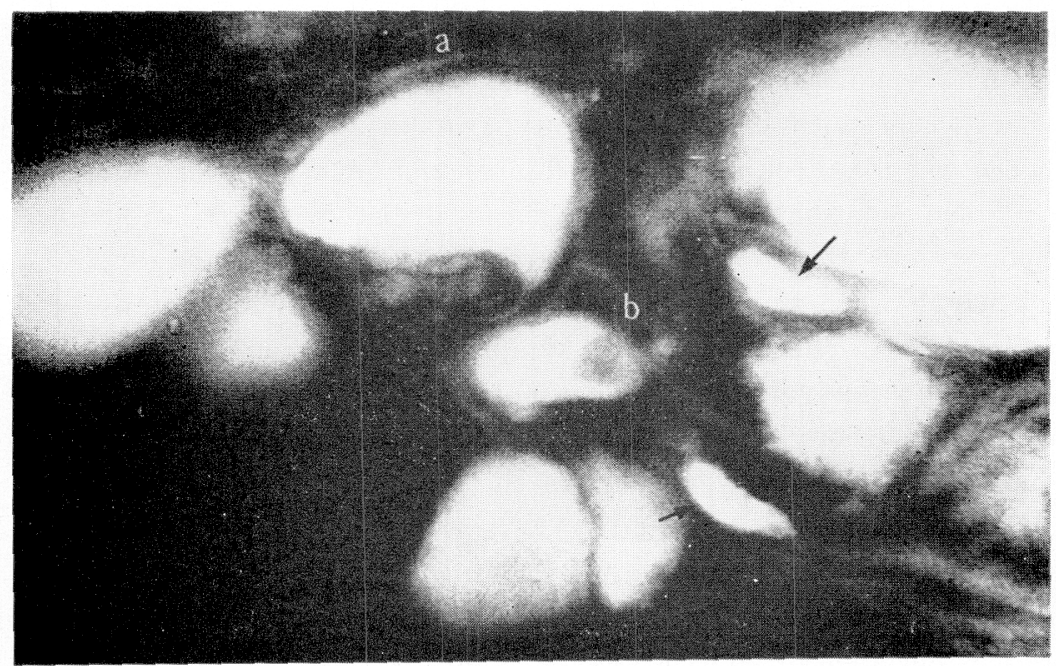

Fig. 2. Fluorescence in various neurons. Large neurons might be sB neurons and small might be $\mathrm{SC}$ neuron in view of their soma size. Mean of long and short axis of neuron $\mathrm{a}$ is about 35 micra and $\mathrm{b}$ is about 18 micra (see diameter histogram in previous paper). Arrows show the yellowish green fluorescent axons which might be assumed to be myelinated B axons. $\times 400$. 


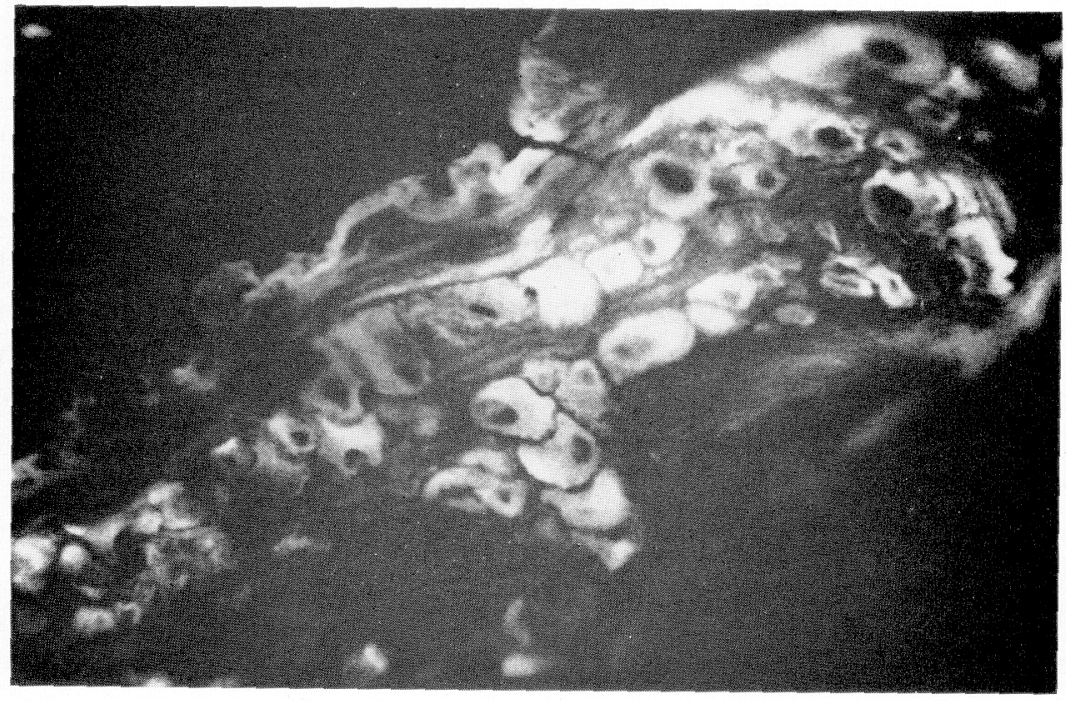

FIG. 3. The nuclei of the fuorescent neurons are indicated as the fluorescence negative round or oval area in the soma. $\times 100$.

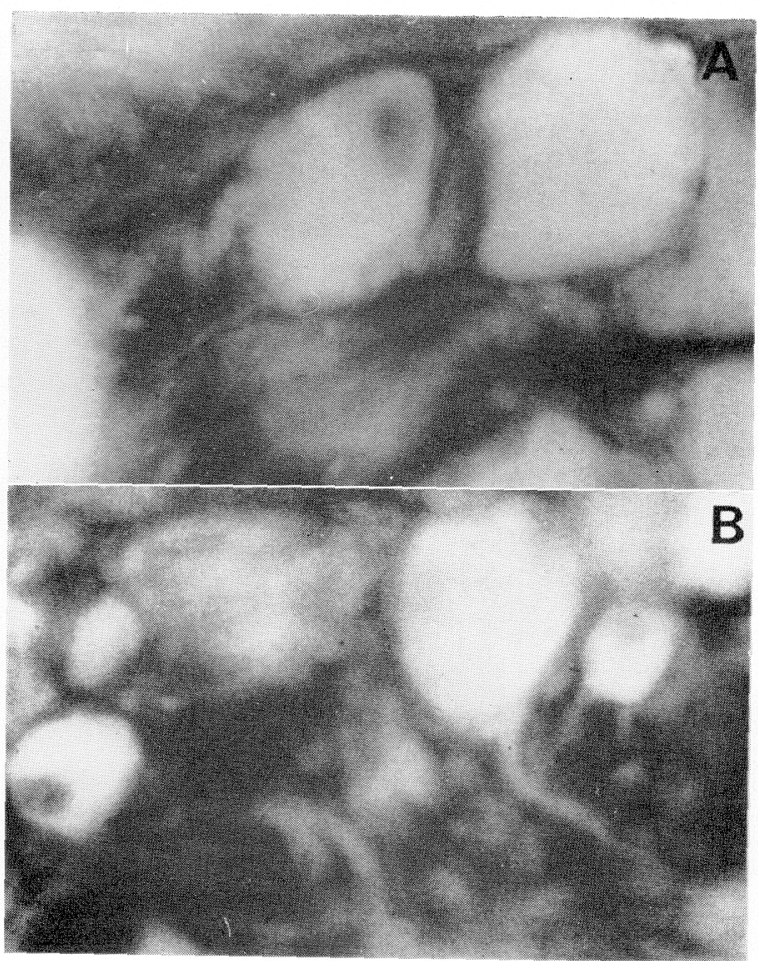

FIG. 4. Axons just leaving from the neuron somata. $\times 400$. 
sidered to terminate on them seen in sympathetic ganglia of mammals (Norberg and SJÖqvist, 1966), were not recognized in this material as in the case of frog (Rana temporaria) (NoRBERG and McIsAC, 1967).

The existence of chromaffin cell islets in the toad sympathetic ganglia was described in the previous paper, and the yellow to brown fluorescent areas or masses seen here and there in the sympathetic ganglia were supposed to be the chromaffin cell islets. It was difficult to recognize each of their components because of their intense homogeneous yellow fluorescence.

It was difficult to reduce completely the fluorescence of the sympathetic neurons by reserpinization under the conditions in these tests (see methods), and slight green fluorescence was visible. However it was remarkably poorer than that of the non-reserpinized ganglia used as the controls. The chromaffin cell islets seen in the ganglia were also resistent to reserpinization, and a fairly intense yellow fluorescence was seen after reserpinization.

Changes of fluorescence and the contour of the neurons were visible in the preparations of which pre- and postganglionic fibres were cut off. Neuron somata were shrinked or distorted in shape and green fluorescence was almost completely disappeared. Even if it was possible to see a weak fluorescence, it was yellowish and not distributed homogeneously in the soma
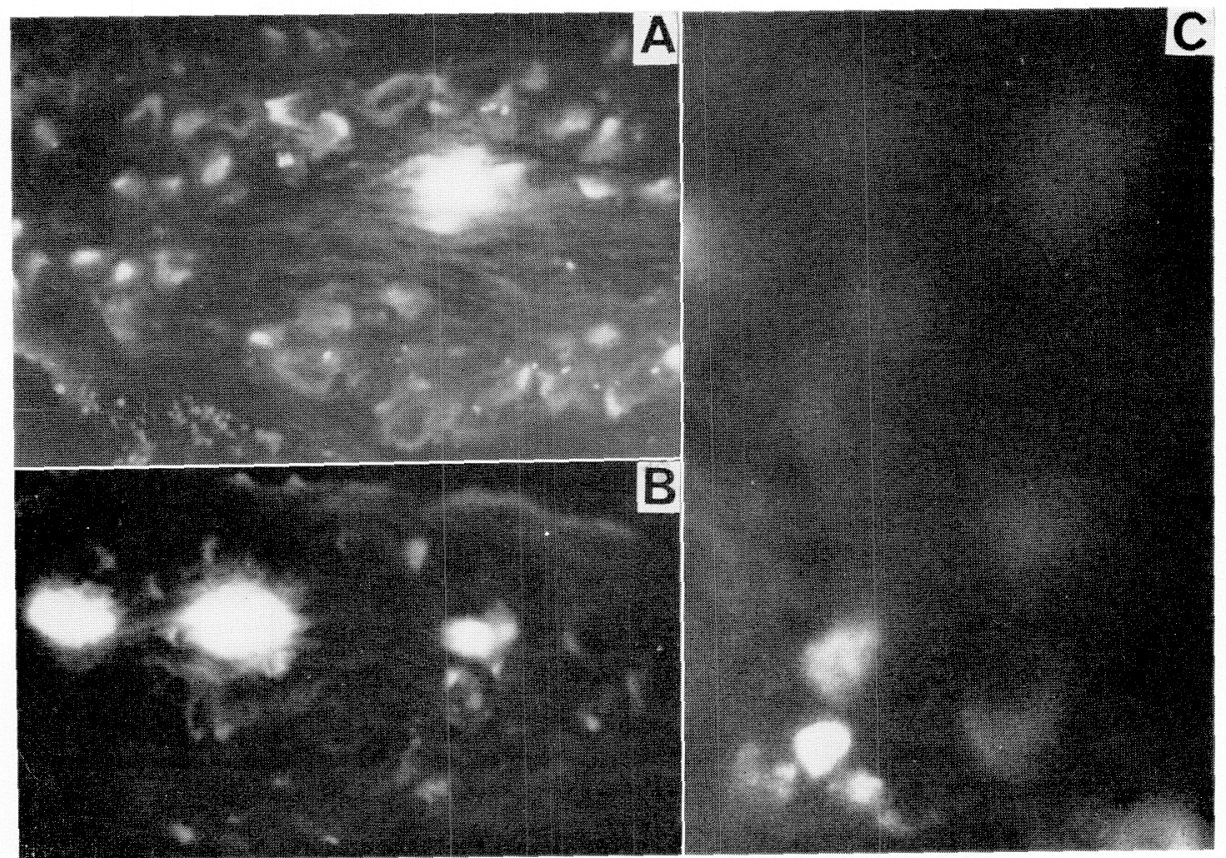

Fig. 5. Fluorescence persistency of chromaffin cell islets. 14 days after cutting pre- and postganglionic fibres of the prevertebral sympathetic ganglion. A, B. $\times 100$. C. $\times 400$. 
(FIG. 5A). In contrast, the chromaffin cell islets showed fairly intense yellow fluorescence (FIG. 5A, B and C). Clear intense green fluorescence was, of course, seen in the intact ganglia used as the controls at the same time under the same conditions.

Sodium borohydride treatment reduced the fluorescence of the neurons and it reappeared after incubation with formaldehyde gas. Chromaffin cell islets were resistent to this treatment and yellow fluorescence remained after the green fluorescence of the neurons was almost completely reduced.

The other sympathetic ganglia except ninth and tenth sympathetic ganglia

On the ganglia from which the splanchnic nerve originated, the findings were the same as on ninth and tenth sympathetic ganglia. Green fluores-

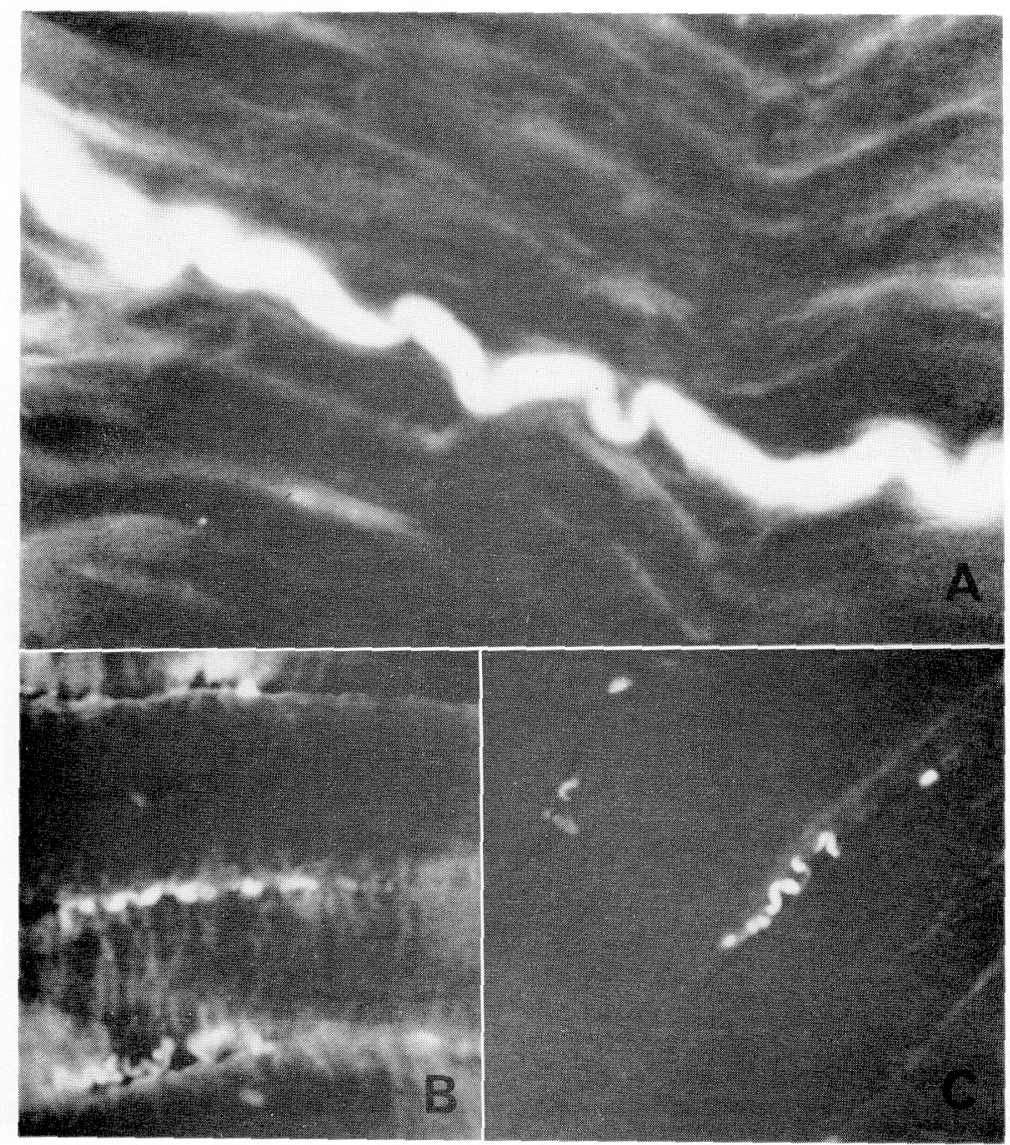

Fig. 6. A. Fluorescent nerve bundle seen in the spinal nerve. $\times 400$.

B. Fluorescent nerve bundle between the atrium cardiac muscle fibres. $\times 100$.

C. Fluorescent nerve bundles seen between the skelctal muscle fibres (gastrocnemius). $\times 100$. 
cence was seen in various neurons with varying intensities. The S. I. F. celllike components and the network of fluorescent nerve terminals on the ganglion cells were not found.

The yellow mass (in fresh preparations) where the bilateral splanchnic nerve fused, which was assumed to be the ganglion, consisted of a small number of neurons and much larger of chromaffin cell islets i.e. neurons were scattered in clusters in small numbers here and there surrounded by dense masses of chromaffin cells. Their intense yellow fluorescence surpassed and covered the neurons. These structures and components were confirmed by ordinary light microscopinc preparations fixed in osmium tetroxide. A network of fluorescent nerve terminals on the neurons in the ganglion and S.I. F. cell-like component was not encountered in these ganglia either.

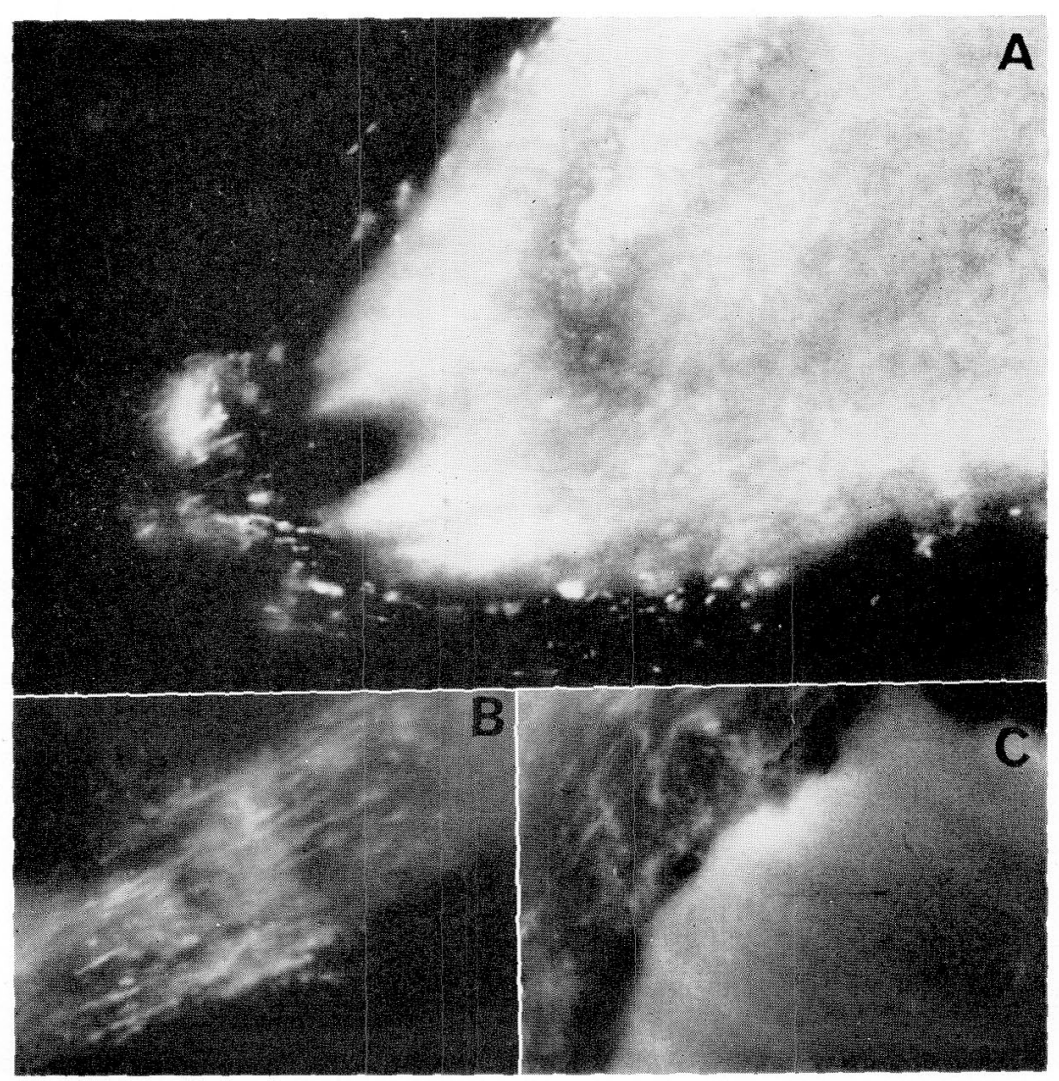

FIG. 7. A. Intense green fluorescent nerve fibres around the toxic gland of the skin. $\times 100$

B. Loose bundle of green fluorescent nerve fibres running to the toxic gland. $\times 100$.

C. Green fitrorescence seen around the toxic gland. $\times 100$. 
The fluorescent nerve bundles

In the spinal nerves, bundles of nerve fibres were often found, of which fluorescence was green to yellowish green (FIG. 6A). These bundles were found in the atrium and gastrocnemius muscle in small numbers and they showed a remarkably tortous course (FIG. 6B, C).

\section{The toxic gland of the skin}

Greenly fluorescent nerve fibres run in clusters across the skin at irregular intervals (FIG. 7B) and it was possible to see them aproaching the bottom of the toxic gland (FIG. 7A). Some of them run further around the wall of the toxic gland (FIG. 7A). In preparations stained with hematoxylin-eosin, van Gieson and Bodian method, smooth muscle-like cells surrounded the inner layer of the secretory cells of the toxic gland. The former were spindle-like in shape with a spindle-like nucleus, and the latter were cuboidal perykarya and had a round or oval nucleus. The picture which would show the fluorescent nerve terminals on the smooth muscle-like cells could not be obtained (FIG. 7C). The substances in the lumen of the toxic gland usually showed yellow fluorescence.

\section{DISCUSSION}

Chromaffin cell islets in the sympathetic ganglia and the adrenal medullary cells showed usually yellow to brown or sometimes green fluorescence (FIG. 8A). In the carotid labyrinth, a large number of yellow to green fluorescent cells were seen (FIG. 8B, C). These yellow fluorescences might be due to the high content of catecholamines or prolonged formaldehyde gas treatment or both (FALCK and OWMAN, 1965).

Both $\mathrm{sB}$ and $\mathrm{SC}$ neurons would be adrenergic or catecholamine containing neurons; at least judging from the green fluorescence in the various size neurons, reduction of fluorescence by reserpinization and sodium borohydride treatment and reappearance with formaldehyde gas incubation. It was impossible to determine whether $\mathrm{sB}$ and $\mathrm{sC}$ systems might have different types of transmitters, and to determine which of the catecholamines, dopamine, adrenaline or noradrenaline, are the dominant containers in toad sympathetic ganglia, because microspectrophotofluorometry and chemical analyses were not performed.

In the frog heart, von EULER (1946) pointed out that the adrenaline is the dominant catecholamines and supposed that adrenaline might play the role of neurotransmitters instead of noradrenaline in mammals. ANGELAKOS et al. (1965) found the predominant content of adrenaline in the heart of frog and toad. Azuma et al. (1965) also found a high content of adrenaline in the brain, heart, sympathetic chain and adrenal medulla of the bullfrog. In 


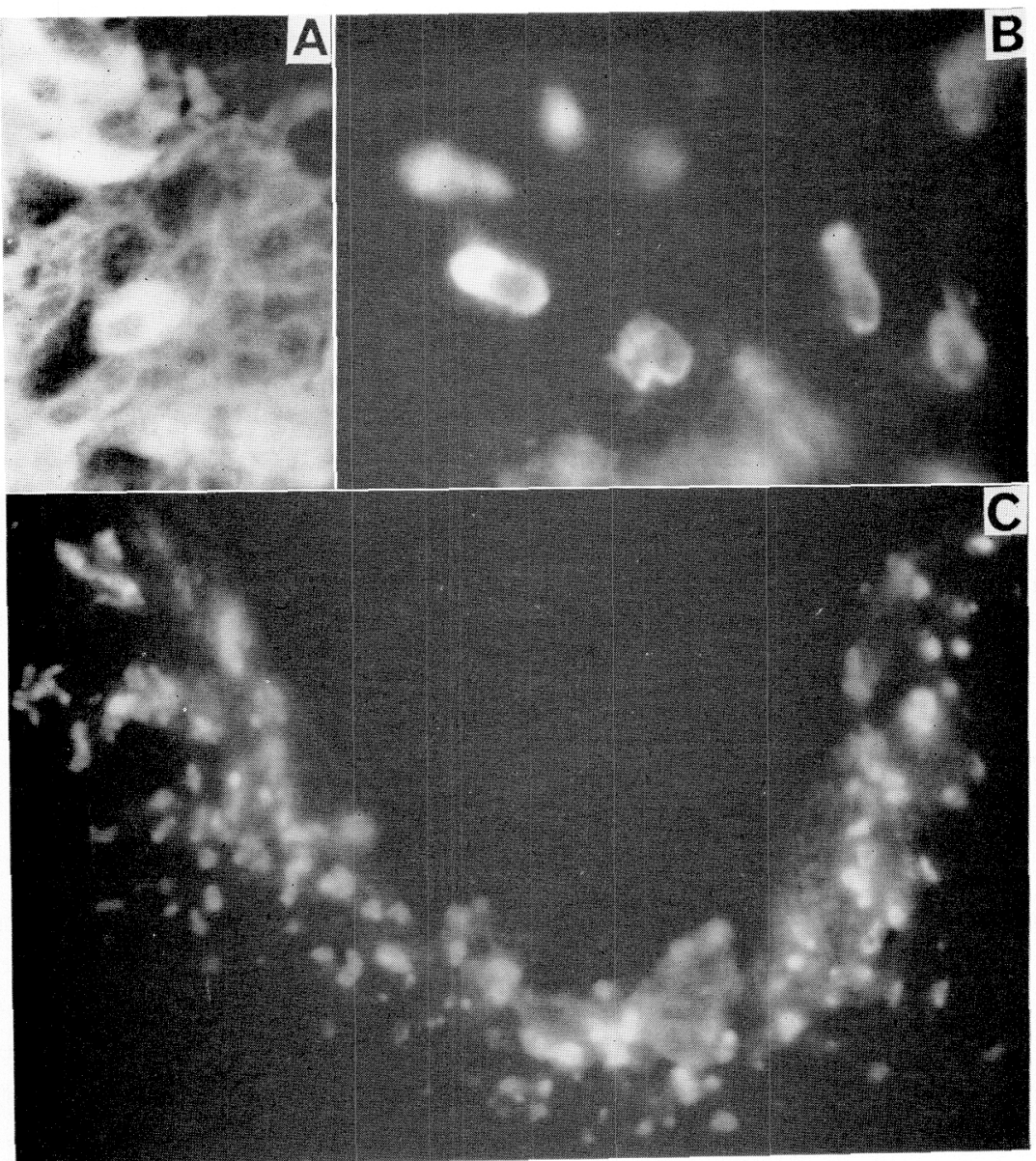

Fig. 8. A. Adrenal medullary cells. $\times 400$.

B. Fluorescent cells in the carotid labyrinth. $\times 400$

C. Carotid labyrinth (general view). $\times 100$.

contrast to organs such as brain, heart, liver, skeletal muscle and spleen, the sympathetic chain and the adrenal medulla contained more noradrenaline than adrenaline. This was supposed to be due to the presence of chromaffin cells in the sympathetic chain (Azuma et al., 1965).

BANISTER et al. (1967) found a high content of adrenaline in the frog carotid labyrinth (Rana temporaria). It would be possible that the green fluorescence seen in the toad sympathetic ganglia and the nerve fibres encountered in various organs such as atrium, gastrocnemius muscle and stomach (FIG. 9) might be chiefly due to adrenaline though there are no chemical analyses and microspectrophotofluorimetric data on toad sympathetic system.

Fluorescence persistency of chromaffin cells in the sympathetic ganglia 
after cutting off of their pre- and postganglionic fibres might be due to, not only to the fact that they contained a higher content of catecholamines which, remarkably, was not depleted or diffused for 14 days after the operation, but also that they were not influenced by the operation at all because they have no long processes or fibres.

Many authors reported that the catecholamines cause inhibitory influence on the transmission processes of the sympathetic ganglia (MARRAzI, 1939: ECCles and LiBeT, 1961: Brodie and Costa, 1961: Weir and MClennAN, 1963). If chromaffin cells in the ganglia are innervated by cholinergic preganglionic nerve fibres, and catecholamines in them might be released by impulses, released catecholamines might have an inhibitory effect on the activity of postganglionic neurons. If they are present in the frog sympathetic ganglia and confirmed to be innervated by preganglionic fibres, they might be concerned with the slow inhibitory postsynaptic potentials (SIPSP) recorded in the frog sympathetic neurons (Rana catesbiana) (TosAKA et al., 1968: Nishi and Koketsu, 1966: Koketsu and Nishi, 1967).

The authors recorded the spontaneous positive deflections from 0.5 to $3 \mathrm{mV}$. together with miniature excitatory postsynaptic potentials in the same neuron of the toad sympathetic ganglia (Honma and KoyAno, 1966). KOKETsU and NisHi proposed that slow inhibitory postsynaptic potentials would be associated with the electrogenic sodium pump (NisHi and KoKETSU, 1967 : Nishi and Koketsu, 1968). It is probable that catecholamines released

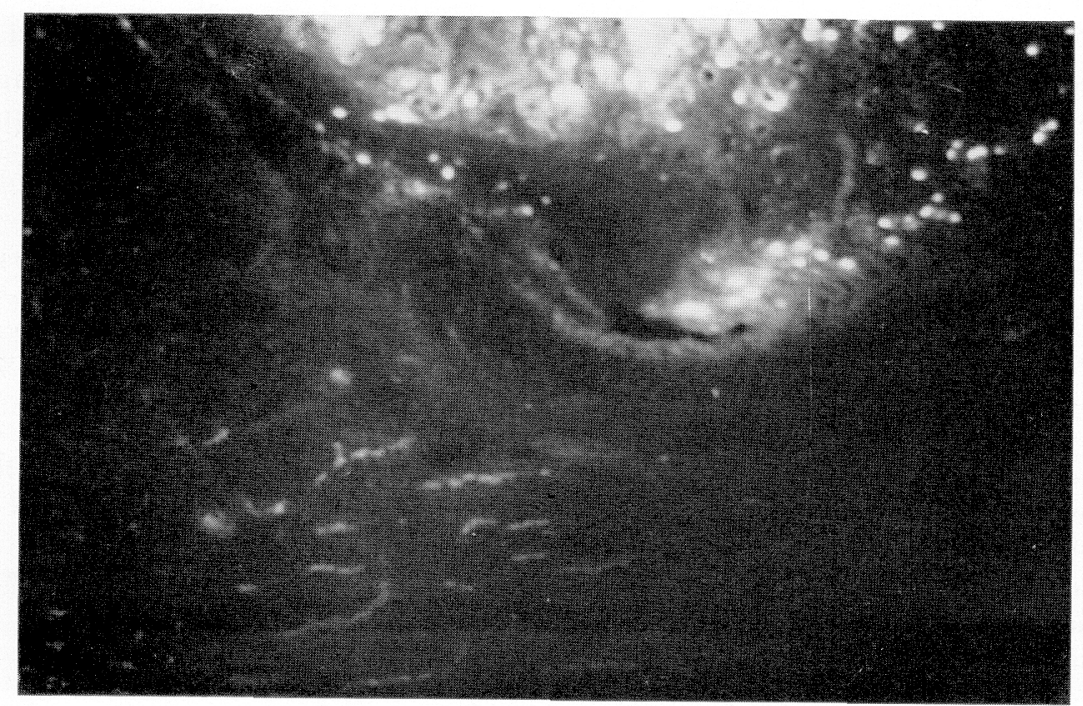

Fig. 9. Fluorescent nerve bundles seen in the muscle layer of stomach. $\times 100$. 
from the chromaffin cells might change the activity of an electrogenic sodium pump connected to the postsynaptic neuronal membrane.

It was impossible to discern whether the fluorescent nerve fibres seen in the spinal nerve, atrium, gastrocnemius muscle and the muscle layer of stomach (FIG. 9), were the bundles of nonmyelinated, myelinated or mixed, in the histochemical preparations. It was neither possible to discern whether the nerve fibres which were supposed to innervate the toxic gland were the nonmyelinated, myelinated or mixed bundles of nerve fibres.

The fluorescent nerve fibres running to the toxic gland and found in the vicinity of the toxic gland might innervate the smooth muscle-like cells surrounding the secretory cells of the toxic gland. They would contain catecholamines as they showed green fluorescence and it was supposed by potential recording that they originated from the sympathetic ganglia, which consisted of various size neurons with varying intensities of green fluorescence. The smooth muscle-like cells around the toxic gland might be the analogue of the myoepithelium.

\section{SUMMARY}

With the aid of histochemical procedures developed by Falck and Hillarp, the lumber sympathetic ganglia and the toxic gland of the lower limb of the toad (Bufo vulgaris japonica) were examined.

1. Both $\mathrm{sB}$ and $\mathrm{SC}$ systems were considered to be adrenergic or catecholamine containing ones.

2. The toxic gland of the lower limb was supposed to be innervated by adrenergic nerve fibres originated from $\mathrm{sB}$ neurons in the sympathetic ganglia. 3. These nerve fibres which were supposed to innervate the toxic gland were assumed to innervate the smooth muscle-like cells surrounding the secretory cells of the toxic gland.

4. The function of chromaffin cells in the sympathetic ganglia was briefly discussed.

\section{REFERENCES}

Angelakos, E. T., P. M. Glassman, R. W. Millard and M. King: Regional distribution and subcellular localization of catecholamines in the frog heart. Comp. Biochem. Physiol. 15 : 313-324, 1965.

Azuma, T., A. Binia And M. B. Visscher: Adrenergic mechanisms in the bullfrog and turtle. Am. J. Physiol. $209:$ 1.287-1294, 1965.

Brodie, B. B. And F. Costa: Hypertension, ed. by A. N. Brest and J.H. Meyer. Lea and Febiger, Philadelphia, 354-360, 1961.

Corrodi, H., N.-̊. Hillarp and G. Jonsson: Fluorescence method for histochemical demonstration of monoamines. 3. Sodium borohydride reduction of the fluorescent compounds as a specificity test. J. Histochem. Cytochem. 12:582-586, 1964. 
Costa, E., A. M. Revzin, R. Kuntzman, S. Spector and B. B. Brodie: Role for ganglionic norepinephrine in sympathetic synaptic transmission. Science 133: 18221823, 1961.

Eccles, R. M. AND B. Libet: Origin and blockade of the synaptic responses of curarized sympathetic ganglia. J. Physiol., (Lond.), 157: 484-503, 1961.

Euler, U.S. V.: A specific sympathetic ergone in adrenergic nerve fibre (Sympathin) and its relation to adrenaline and noradrenaline. Acta Physiol. Scand. 12: 73-97, 1946.

FAlck, B. AND $\mathrm{C}_{\mathrm{H}}$. OWMAN: A detailed methodological description of the fluorescence method for the demonstration of biogenic monoamines. Acta Univ. Lund., Sectio 7: 1-23, 1965.

Honma, S.: Fluorescence microscopic observations on the brain of the lamprey, Lampetra japonica. Arch. Histol. Jap. 31:167-178, 1969.

Honma, S.: Functional differentiation in $\mathrm{sB}$ and $\mathrm{sC}$ neurons in the toad sympathetic ganglia. Jap. J. Physiol. (in preparation).

Honma, S. AND H. Koyano: Sodium ion effects on synaptic transmission of toad sympathetic ganglion. J. Physiol. Soc. Jap. $28: 424,1966$. (in Japanese).

Koketsu, K. AND S. Nishi: Characterization of the slow inhibitory postsynaptic potentials of bullfrog sympathetic ganglion cells. Life Sci. 6: 1827-1836, 1967.

Marazzi, A.S.: Electrical studies on the phamacology of autonomic synapses II. The action of a sympathomimetic drug (epinephrine) on sympathetic ganglia. J. Pharmacol. 65 : 395-404, 1939.

Nishi, S. AND K. KoKetsu: Late after discharge of sympathetic postganglionic fibres. Life Sci. 5 : 1991-1997, 1966.

Nishi, S. And K. Koketsu: Origin of ganglionic inhibitory postsynaptic potential. Life Sci. 6: 2049-2055, 1967.

Nishi, S. AND K. Koketsu: Analysis of slow inhibitory postsynaptic potential of bullfrog sympathetic ganglion. J. Neurophysiol. 31: 717-728, 1968.

Norberg, K., M. Ritzen and U. Ungerstadt: Histochemical studies on a special catecholamine containing cell type in sympathetic ganglia. Acta Physiol. Scand. $67: 260-270,1966$.

Norberg, K. AND F. SJÖQVIST: New possibilities for adrenergic modulation of ganglionic transmission. Pharmacol. Rev. 18: No. 1 of part 1. 743-751, 1966.

Norberg, K. AND R. J. McIsac: Cellular location of adrenergic amines in frog sympathetic ganglia. Experientia 23/12 1052, 1967.

TosakAn, T., S. Chichibu AND B. Libet: Intracellular analysis of slow inhibitory and excitatory postsynaptic potentials in sympathetic ganglia of the frog. J. Neurophysiol. 31 : 396-409, 1968.

Weir, M.C.L. And H. Molennan: The action of catecholamines in sympathetic ganglia. Canad. J. Physiol. $41: 2627-2636,1963$. 